Resumo

\title{
Análise da concordância entre diferentes índices da composição corporal em alunas do Colégio Militar do Rio de Janeiro
}

Thiago Fraga Mello Bsci, Marcos Fortes PhD

Introdução: Embora estudos sobre a concordância entre índices da composição corporal tenham sido feitos para o público masculino do Exército Brasileiro, a literatura apresenta-se carente quanto a investigações direcionadas ao segmento feminino na Linha Militar Bélica.

Objetivo: Investigar a associação entre quatro diferentes índices assim como a concordância entre eles.

Métodos: Participaram do estudo 18 adolescentes do sexo feminino, saudáveis, estudantes do Colégio Militar do Rio de Janeiro, com média de 16,2 $( \pm 1,5$; Máx $=$ 19, Mín =14) anos, massa corporal média de 56,6 ( $\pm 6,6$; Máx = 66,8, Mín = 43,4) $\mathrm{kg}$ e estatura média de 160,4 ( $\pm 4,6$; Máx = 169, Mín =154) $\mathrm{cm}$. A coleta de dados constituía da mensuração de cinco medidas antropométricas, incluindo massa corporal $(\mathrm{kg})$; estatura em pé $(\mathrm{cm})$; estatura sentada $(\mathrm{cm})$; e dobras cutâneas tricipital e subescapular (mm). Além disso, foi realizado o exame de Absortometria de Raios-X de Dupla Energia (DEXA).

Resultados: Todas as participantes do estudo já se encontram na situação de pós-estirão em relação ao pico de velocidade de crescimento e observou-se diferença significativa na aplicação do teste $t$ de Student entre o percentual de gordura pela Fórmula de Slaughter e pelo iDEXA, com uma média significativamente maior para o segundo método. Os resultados da aplicação do Coeficiente de Correlação de Pearson entre os diferentes índices utilizados no estudo mostram que há associação significativa entre eles, entretanto, analisando-se o índice Kappa entre todos os métodos, observa-se que os índices de concordância foram considerados fracos.

Conclusão: Foram encontradas correlações estatisticamente moderadas entre os métodos indicadores de estado nutricional, entretanto com concordância pobre entre eles. Os altos valores de correlação não garantiram a convergência para o mesmo diagnóstico nutricional na população estudada. 